Research Article

\title{
Using the Grey Model to Analyze the Impact of the Primary, Secondary, and Tertiary Industries on the Public's Attention to Air Pollution in Three Cities
}

\author{
Haolei Gu $\mathbb{D D}^{1}$ and Yan Chen $\mathbb{i D}^{2}$ \\ ${ }^{1}$ Faculty of Management and Economics, Kunming University of Science and Technology, Kunming, Yunnan 650093, China \\ ${ }^{2}$ School of Economics and Management, Hebei University of Engineering, Handan 056038, China \\ Correspondence should be addressed to Yan Chen; 964129856@qq.com
}

Received 12 November 2020; Revised 2 December 2020; Accepted 12 December 2020; Published 19 December 2020

Academic Editor: Yun Bai

Copyright (c) 2020 Haolei Gu and Yan Chen. This is an open access article distributed under the Creative Commons Attribution License, which permits unrestricted use, distribution, and reproduction in any medium, provided the original work is properly cited.

To analyze the impact of the added value of primary, secondary, and tertiary industry on public attention to air pollution in Handan, Xingtai, and Shijiazhuang, Baidu index is used to build the air pollution attention index. Taking the added value of the primary, secondary, and tertiary industry as the influencing factors, fractional grey multivariable convolution model is used to predict and analyze the public attention to air pollution in these three cities from 2020 to 2024. The results show that the secondary industry has the greatest impact on the public's attention to air pollution compared with the primary industry and the tertiary industry. And the added value of the secondary industry with faster increase will cause a faster increase in the public's air pollution attention from 2020 to 2024, especially in Handan. It is not only helpful to air pollution control, but also helpful in solving the public psychological problems caused by air pollution.

\section{Introduction}

Air pollution has always been the key issue of environmental protection, which causes certain harm to human beings and nature [1]. The harm of air pollution is manifold. First of all, air pollution poses a threat to human health. It can not only cause respiratory diseases such as bronchitis, asthma, emphysema, and lung cancer [2], but also cause serious psychological problems such as anxiety, fear, irritability, and depression [3]. Secondly, air pollution will harm the growth of plants and yield decline and quality damage [4]. Finally, air pollution seriously affects the climate [5]. Excessive air impurities will increase precipitation. Excessive substances such as sulfur dioxide and carbon dioxide can easily lead to acid rain and greenhouse effect. Therefore, the causes of air pollution have been widely studied [6]. In fact, except for a few natural causes, air pollutants are mostly produced by human activities. Among them, industrial production is the main source of air pollutants [7].

In recent years, due to the accelerating process of industrialization and urbanization, air control has become more difficult [8]. Traditional air pollution prevention measures, such as strengthening greening and promoting clean energy, can effectively reduce air pollution $[9,10]$. However, these methods not only require great efforts, but the whole process may take a long time. In fact, we can prevent and control air pollution by understanding the public's attention about air quality [11]. Individual's attention to air quality can reflect air quality more effectively [12]. More targeted air quality control measures can be obtained from the perspective of attention [13]. The attention is used to analyze the evolution trends of fog and haze in time and space [14]. The differences of smog attention in China are discussed by multiple regression models 
for improving air quality [15]. The public's willingness to improve air quality in six cities was studied [16]. However, These studies of attention are rarely combined with the causes of air pollution. In fact, air pollution is mainly caused by industrial production in most cities, especially in places with serious air pollution [17]. Therefore, we will analyze the public's attention to air pollution from the perspective of industrial development.

Considering the timeliness of data and the process of urban development, the available annual data of industry is limited. Therefore, the study of public's attention to air pollution is carried out on the grey model. Grey prediction theory was put forward by Professor Deng to solve the problem of uncertain data or small samples. In recent years, grey prediction model has attracted more and more attention because of its remarkable effect [18-20]. In the case study of e-waste data in Washington, the nonlinear grey Bernoulli model with convolution integral is optimized by using particle swarm optimization algorithm [21]. Ma used an algorithm to optimize the unbiased fractional discrete multivariate grey model to explore the relationship between power consumption and its related factors [22]. In order to predict the power consumption in Shandong Province, $\mathrm{Wu}$ optimized the multivariate grey model with fractional-order accumulation by changing the order [23]. Ding designed the lion ant colony optimization algorithm to determine the optimal cumulative coefficient, which further improved the prediction ability of the grey model [24]. In order to discuss the relationship between emissions and economic growth, the unequal gap grey Verhulst model is derived [25].

In addition, many scholars have also applied the grey model to the study of air quality [26-28]. However, few people use grey model to predict public attention to air pollution. Therefore, the added value of the primary, secondary, and tertiary industries was taken as the influencing factor, and the grey multivariate convolution model is used to predict and analyze the public's attention to air pollution. The innovations of this paper are as follows: (1) Based on Baidu index, the measurement method and prediction model of air pollution attention are put forward. (2) The air pollution attention of Handan, Xingtai, and Shijiazhuang from 2020 to 2024 is predicted and analyzed by using the proposed prediction model. The research results will help improve air pollution and public mental health.

The rest of this paper is organized as follows. The research area, measurement of air pollution attention, and data sources are given in Section 2. The models and methods used are introduced in Section 3. Section 4 analyzed the influence of industrial added value on air pollution attention in Handan, Xingtai, and Shijiazhuang. Section 5 is the conclusion and suggestions.

\section{Research Area and Date Sources}

2.1. Research Area. As shown in Figure 1, Handan, Xingtai, and Shijiazhuang are located in Beijing-Tianjin-Hebei region, China, and have been suffering from serious air pollution for many years [29-31]. Generally speaking, air pollution problems in this area mainly come from the following aspects: first, industrial production. Industries of coal and chemical in this area are relatively developed, which emit a large amount of waste gas during production. As Beijing is the capital of China, great efforts have been made to control air pollution. As a result, some enterprises with serious industrial pollution around Beijing have been removed to the south, which has further aggravated the air pollution in Handan, Xingtai, and Shijiazhuang [32, 33]. Secondly, coal is the main fuel in this area, and a large amount of sulfur dioxide is released during combustion, which leads to serious air pollution [34]. Thirdly, automobile exhaust and land dust have aggravated air pollution.

Because of the serious air pollution in Handan, Xingtai, and Shijiazhuang, the environmental protection investment of the government and enterprises is too deficient to meet the local pollution control needs [35]. Therefore, better methods need to be explored. As a matter of fact, there are many benefits by using the power of the public. First of all, the public is exposed to the air all the time, so they have a real feeling of air pollution. Secondly, the public's life covers every corner of the city, so they can find pollution sources for the first time. Thirdly, the daily communication of the public connects the scattered information and finds potential information about air pollution. Finally, information from the public is easy to collect, which can reduce the cost of information acquisition. Therefore, studying the public's attention of air pollution is very beneficial to the prevention and control of air pollution in Handan, Xingtai, and Shijiazhuang.

2.2. Attention of Air Pollution. Internet search data is generated by the spontaneous Internet search behavior of the public and is characterized by real-time and openness $[36,37]$. Internet search behavior can effectively reflect the public's thoughts [38-40]. When the air quality changes, the daily life of the public will be affected to some extent. Due to the lack of knowledge about air pollution, the public tends to search the Internet for information. Therefore, Internet search data can be used to measure the public's concern about air pollution.

According to the 2019 Hebei Internet Development Report released by Hebei Communications Administration (https://hbca.miit.gov.cn/), by the end of 2019, the provincial Internet export bandwidth, the total length of optical cable lines, the number of mobile phone base stations, Internet broadband access ports, and fixed broadband access users all rank 7 th in the country, and the number of IPTV users ranks 6th in China. The access rate of optical fiber broadband and the coverage rate of $4 \mathrm{G}$ signals in administrative villages of the province reach over $99 \%$. This shows that public Internet search data related to air pollution can well reflect the public's attention to air pollution.

Baidu is the largest search engine in China. Therefore, Baidu index is taken as the information source of network search to get the attention of air pollution in Handan, Xingtai, and Shijiazhuang from 2014 to 2019. Firstly, based on pollution sources, pollution prevention, natural factors, and pollution hazards, a logical chain is built. Secondly, 


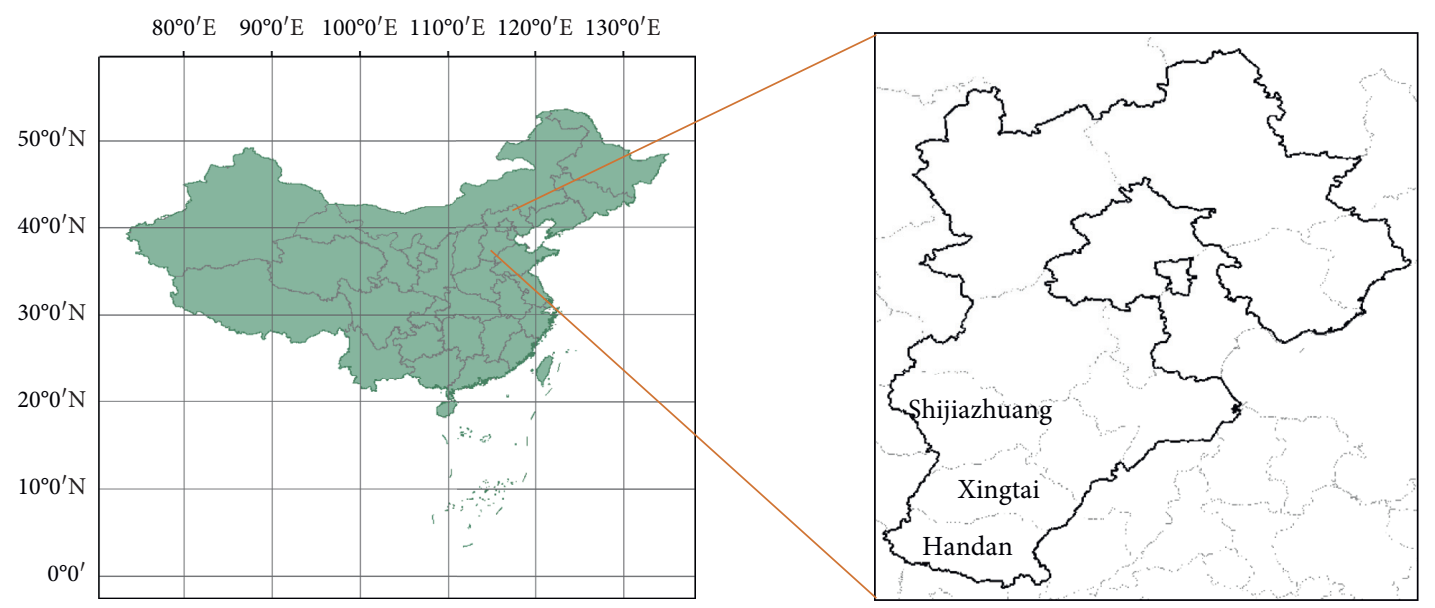

Figure 1: Geographical location of Handan, Xingtai, and Shijiazhuang in China.

"environmental protection" is chosen as the benchmark keyword to expand the entry by using the hot word recommendation function of the search engine. The general vocabulary of air quality is added to get all the search keywords. Finally, the keyword and logic chain are integrated to get the result of Figure 2. As shown in Figure 2, a total of 18 keywords were obtained. The air pollution attention of Handan, Xingtai, and Shijiazhuang from 2014 to 2019 was obtained by adding up the Baidu index of the 18 keywords. The results are shown in Table 1.

2.3. Industry Data. In order to study the future air quality in Handan, Xingtai, and Shijiazhuang, we need to know the future air attention. Since the air pollution in Handan, Xingtai, and Shijiazhuang is mainly caused by economic development, we collected the added value of the primary, secondary, and tertiary industries in Handan, Xingtai, and Shijiazhuang from 2014 to 2019 from Hebei Statistics Bureau (http://tjj.hebei.gov.cn/).

\section{Methods}

3.1. Fractional Grey Multivariable Convolution Model. Grey prediction model is widely concerned because of its effectiveness in short time series prediction. $\operatorname{GMC}(1, N)$ model obtained by Tien et al. improved the traditional $\mathrm{GM}(1, N)$ model and showed good performance in shortterm prediction [41]. After that, $\mathrm{Wu}$ et al. further improved the GMC $(1, N)$ model via fractional accumulation (FGMC $(1$, $N)$ ). $\operatorname{FGMC}(1, N)$ model is superior to the existing grey multivariate models such as $\operatorname{GMCT}(1, N), \operatorname{GMCG}(1, N)$, and $\operatorname{RDGM}(1, N)[23]$. Therefore, we use the $\operatorname{FGMC}(1, N)$ model to predict the attention of air pollution. The derivation process of the $\operatorname{FGMC}(1, N)$ model is as follows.

The original nonnegative sequence is conventionally represented as

$$
\begin{aligned}
X_{j}^{(0)} & =\left\{x_{j}^{(0)}(1), x_{j}^{(0)}(2), \cdots, x_{j}^{(0)}(n)\right\}, \\
j & =1,2, \ldots, m .
\end{aligned}
$$

Step 1: by using $x_{j}^{(r)}(k)=\sum_{i=1}^{k} C_{k-i+r-1}^{k-i} x_{j}^{(0)}(i)$, the $\mathrm{r}$-order accumulation sequence is

$$
X_{j}^{(r)}=\left\{x_{j}^{(r)}(1), x_{j}^{(r)}(2), \cdots, x_{j}^{(r)}(n)\right\}
$$

where $C_{r-1}^{0}=1, C_{k}^{k+1}=0, C_{k-i+r-1}^{k-i}=((k-i+r-1)$ $(k-i+r-2) \cdots(r+1) r /(k-i) !)$.

Step 2: the whitened equation of $\operatorname{FGMC}(1, N)$ model is written as

$$
\begin{aligned}
\frac{\mathrm{d} x_{1}^{(r)}(t)}{\mathrm{d} t} & +b_{1} x_{1}^{(r)}(t)=b_{2} x_{2}^{(r)}(t)+b_{3} x_{3}^{(r)}(t) \\
& +\cdots+b_{m} x_{m}^{(r)}(t)+u,
\end{aligned}
$$

where $b_{1}, b_{2}, \ldots, b_{m}$ are parameters and $u$ is the control parameter. The least-squares solution of the model parameters is

$$
\left[\widehat{b}_{1}, \widehat{b}_{2}, \cdots, \widehat{b}_{m}, \widehat{u}\right]^{T}=\left(B^{T} B\right)^{-1} B^{T} Y
$$

where 


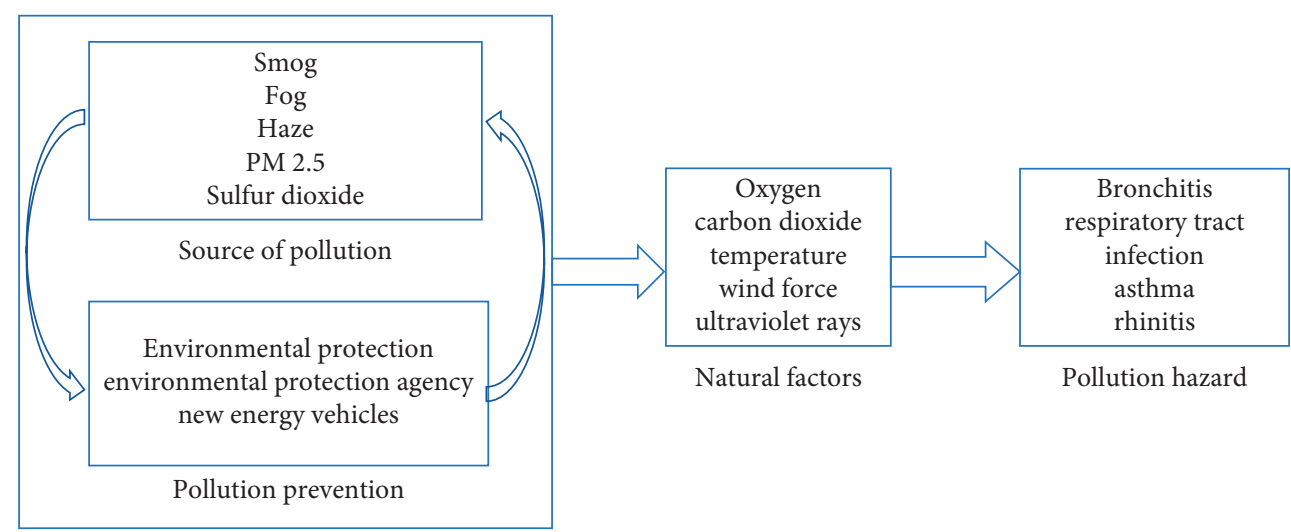

Figure 2: Baidu index keyword results.

Table 1: Public attention of air pollution in Handan, Xingtai, and Shijiazhuang.

\begin{tabular}{lccc}
\hline Year & Handan & Xingtai & Shijiazhuang \\
\hline 2014 & 1051 & 831 & 2278 \\
2015 & 1215 & 965 & 2161 \\
2016 & 1124 & 902 & 2128 \\
2017 & 1468 & 1248 & 2418 \\
2018 & 1491 & 1290 & 2286 \\
2019 & 1416 & 1097 & 2168 \\
\hline
\end{tabular}

$$
\begin{aligned}
& Y=\left[\begin{array}{c}
x_{1}^{(r)}(2)-x_{1}^{(r)}(1) \\
x_{1}^{(r)}(3)-x_{1}^{(r)}(2) \\
\vdots \\
x_{1}^{(r)}(n)-x_{1}^{(r)}(n-1)
\end{array}\right], \\
& B=\left[\begin{array}{ccccc}
-\frac{\left(x_{1}^{(r)}(1)+x_{1}^{(r)}(2)\right)}{2} & \frac{\left(x_{2}^{(r)}(1)+x_{2}^{(r)}(2)\right)}{2} & \ldots & \frac{\left(x_{m}^{(r)}(1)+x_{m}^{(r)}(2)\right)}{2} & 1 \\
-\frac{\left(x_{1}^{(r)}(2)+x_{1}^{(r)}(3)\right)}{2} & \frac{\left(x_{2}^{(r)}(2)+x_{2}^{(r)}(3)\right)}{2} & \ldots & \frac{\left(x_{m}^{(r)}(2)+x_{m}^{(r)}(3)\right)}{2} & 1 \\
\vdots & \vdots & \vdots & \vdots & \vdots \\
-\frac{\left(x_{1}^{(r)}(n-1)+x_{1}^{(r)}(n)\right)}{2} \frac{\left(x_{2}^{(r)}(n-1)+x_{2}^{(r)}(n)\right)}{2} & \cdots \frac{\left(x_{m}^{(r)}(n-1)+x_{m}^{(r)}(n)\right)}{2} & 1
\end{array}\right] .
\end{aligned}
$$

Step 3: then, the approximate time-response function of the $\operatorname{FGMC}(1, N)$ model is

$$
\begin{aligned}
\widehat{x}_{1}^{\left(r_{1}\right)}(t)= & x_{1}^{(0)}(1) e^{-b_{1}(t-1)} \\
& +\sum_{\tau=2}^{t}\left\{e^{-b_{1}(t-\tau+0.5)} \frac{f(\tau)+f(\tau-1)}{2}\right\},
\end{aligned}
$$

where

$$
f(t)=b_{2} x_{2}^{\left(r_{2}\right)}(t)+b_{3} x_{3}^{\left(r_{3}\right)}(t)+\cdots+b_{m} x_{m}^{\left(r_{m}\right)}(t)+u \text {. }
$$

Step 4: finally, the sequence by the inverse accumulated generating operator of $r$-order is 


$$
\widehat{x}_{1}^{(0)}(1)=x_{1}^{(0)}(1), \hat{x}_{1}^{(0)}(k)=\widehat{x}_{1}^{\left(r_{1}\right)\left(-r_{1}\right)}(k)-\widehat{x}_{1}^{\left(r_{1}\right)\left(-r_{1}\right)}(k-1), \quad k=2,3, \ldots, n .
$$

3.2. ModelEvaluation. In order to know the prediction effect of the model, it is necessary to evaluate the prediction results of the model. The mean absolute percentage error (MAPE) is simple to calculate and can reflect the difference between the predicted value and the true value, which is often used to test the model. Therefore, in order to compare with the other models and evaluate the prediction effect of the $\operatorname{FGMC}(1, \mathrm{~N})$ model on air pollution attention, we use the MAPE to evaluate the error, and its formula is

$$
\text { MAPE }=\frac{\sum_{t=1}^{n}\left|\left(A_{t}-F_{t}\right) / A_{t}\right|}{n} \times 100 \% .
$$

In order to illustrate the effectiveness of the $\operatorname{FGMC}(1, N)$ model in predicting air pollution attention, it is necessary to compare and analyze its fitting effects. Table 2 shows the added value of Handan's primary, secondary, and tertiary industries from 2014 to 2019 and their proportion to the total added value. Then, $\operatorname{FGMC}(1, N), \operatorname{GMC}(1, N)$, and $\operatorname{DGM}(1, N)$ models are used to analyze the influence of industrial added value on air pollution attention. Taking the primary industry in Handan as an example, the added value of the primary industry is the influencing factor to predict air pollution attention.

For the FGMC $(1, N)$ model, its advantage lies in the introduction of fractional accumulation, which accords with the new information priority of time series prediction. The FGMC $(1, N)$ model process is as follows:

Firstly, the particle swarm optimization is used to optimize the fractional-order $(r=0.054)$. Secondly, through the model process, the $\operatorname{FGMC}^{0.054}(1,2)$ model can be expressed as

$$
\begin{aligned}
& \frac{\mathrm{d} x_{1}^{(0.054)}(t)}{\mathrm{d} t}-0.02197 x_{1}^{(0.054)}(t) \\
& \quad=3.621456 x_{2}^{(0.054)}(t)-1429.85
\end{aligned}
$$

Using eq. (10), we can get the prediction result of air pollution attention under the influence of the primary industry. Similarly, the FGMC $(1,2)$ model under the influence of secondary industry and the tertiary industry is obtained by the PSO optimization algorithm, and then the best fitting result of air pollution attention is obtained as the $\operatorname{FGMC}^{0.00523}(1,2)$ model and FGMC ${ }^{0.470924}(1,2)$ model. The calculation processes of $\operatorname{GMC}(1,2)$ and $\operatorname{DGM}(1,2)$ models are in Reference [41]. Finally, the results of air pollution attention under the influence of different industries are summarized in Table 3.

As an example, FGMC(1) indicates that the primary industry is the influencing factor to establish $\operatorname{FGMC}(1, N)$ model. It can be seen from Table 3 and Figure 3 that the fitting error of $\operatorname{FGMC}^{0.00523}(1,2)$ model is the lowest $(3.91 \%)$, which shows that the fitting effect of FGMC ${ }^{0.00523}(1$, 2) model on air pollution attention is the best with the growing value of the secondary industry. By analyzing the fitting results of different models under the influence of different industries, we can get the following two conclusions. Firstly, the fitting accuracy of the FGMC $(1,2)$ model is higher than that of $\operatorname{GMC}(1,2)$ and $\operatorname{DGM}(1,2)$ models for the same industry as influencing factors, which shows that the FGMC $(1,2)$ model is more suitable for predicting air pollution attention than the other two models. Secondly, for the same model, the added value of the secondary industry can be used as an influencing factor to predict air pollution attention with better accuracy, which shows that the added value of the secondary industry has a better prediction effect on air pollution attention. Therefore, in order to better predict the attention of air pollution, the secondary industry is taken as the influencing factor, and the $\operatorname{FGMC}(1, N)$ model is used to study the attention of air pollution in three cities.

\section{Empirical Study}

4.1. Relationship between the Secondary Industry Added Value and Air Quality Attention in Handan. Handan is located in the southernmost part of Hebei Province and is one of the most polluted cities. Because of the surplus of mineral resources, Handan developed largely with heavy industry. It can be seen from Table 2 that, from 2014 to 2019, the secondary industry in Handan accounted for almost $50 \%$ of the total industry. Over the years, Handan has formed a multipillar industry pattern with metallurgy, building materials, chemical industry, and electric power. These industries are resource-consuming and heavily polluting industries. In particular, Handan Iron and Steel Plant located in the west of Handan emits thick smoke almost day and night. What is terrible is that the winter wind in North China and the pollution sources with the wind diffuse over the whole city. In winter, suffocating smog enveloped the whole city, and the public worried about their health every day, which caused great psychological harm to the public. Therefore, understanding the public's attention to air pollution is conducive to improving the public's mental health. Based on the analysis of industrial structure and pollution sources in Handan, we can predict the public air pollution attention from the development of secondary industry.

Through the model analysis at the end of Section 3, the prediction model of air pollution attention degree based on the secondary industry can be obtained by using the same method:

$$
\begin{aligned}
& \frac{\mathrm{d} x_{1}^{(0.00523)}(t)}{\mathrm{d} t}+0.902474 x_{1}^{(0.00523)}(t) \\
& =2.173904 x_{2}^{(0.00523)}(t)-2227.69
\end{aligned}
$$

In recent years, the rapid development of industry in Handan has resulted in serious air pollution. Although the management of highly polluting enterprises has been strengthened, the smog problem still cannot be effectively 
TABLe 2: Attention to air pollution and added value, proportion of primary, secondary, and tertiary industry in Handan.

\begin{tabular}{|c|c|c|c|c|c|c|c|}
\hline \multirow{3}{*}{$\frac{\text { Year }}{2014}$} & \multirow{3}{*}{$\begin{array}{c}\text { Attention } \\
1051\end{array}$} & \multicolumn{6}{|c|}{ Industry added value (billion yuan) } \\
\hline & & \multicolumn{2}{|c|}{ Primary } & \multicolumn{2}{|c|}{ Secondary } & \multicolumn{2}{|c|}{ Tertiary } \\
\hline & & 403.1 & 0.13 & 1543.5 & 0.50 & 1133.4 & 0.37 \\
\hline 2015 & 1215 & 402.8 & 0.13 & 1500.7 & 0.48 & 1241.9 & 0.39 \\
\hline 2016 & 1124 & 417.2 & 0.13 & 1576.4 & 0.47 & 1343.7 & 0.40 \\
\hline 2017 & 1468 & 405.4 & 0.11 & 1783.7 & 0.49 & 1477.2 & 0.40 \\
\hline 2018 & 1491 & 313.3 & 0.09 & 1558 & 0.45 & 1583.3 & 0.46 \\
\hline 2019 & 1416 & 342.4 & 0.09 & 1554.6 & 0.45 & 1589.1 & 0.46 \\
\hline
\end{tabular}

TABLE 3: The results of three models under the different industries influence.

\begin{tabular}{|c|c|c|c|c|c|c|c|c|c|}
\hline \multirow{3}{*}{ Year } & \multicolumn{9}{|c|}{ Industry added value (billion yuan) } \\
\hline & \multicolumn{3}{|c|}{ Primary industry } & \multicolumn{3}{|c|}{ Secondary industry } & \multicolumn{3}{|c|}{ Tertiary industry } \\
\hline & FGMC & GMC & DGM & FGMC & GMC & DGM & FGMC & GMC & DGM \\
\hline 2014 & 1051.0 & 1051.0 & 1051.0 & 1051.0 & 1051.0 & 1051.0 & 1051.0 & 1051.0 & 1051.0 \\
\hline 2015 & 1087.1 & 1143.4 & 1138.2 & 1114.9 & 1108.4 & 1137.1 & 1128.7 & 1196.3 & 1163.9 \\
\hline 2016 & 1237.4 & 1275.3 & 1293.0 & 1171.0 & 1233.2 & 1274.8 & 1256.1 & 1263.4 & 1252.2 \\
\hline 2017 & 1435.7 & 1385.5 & 1407.9 & 1393.3 & 1359.6 & 1435.9 & 1361.9 & 1337.0 & 1386.9 \\
\hline 2018 & 1473.8 & 1435.2 & 1419.2 & 1473.1 & 1427.6 & 1431.3 & 1411.3 & 1417.2 & 1469.6 \\
\hline 2019 & 1416.0 & 1451.2 & 1454.1 & 1348.8 & 1421.0 & 1427.4 & 1423.1 & 1500.0 & 1445.8 \\
\hline MAPE & $3.99 \%$ & $5.20 \%$ & $5.49 \%$ & $3.91 \%$ & $5.08 \%$ & $4.47 \%$ & $5.32 \%$ & $5.62 \%$ & $4.11 \%$ \\
\hline
\end{tabular}

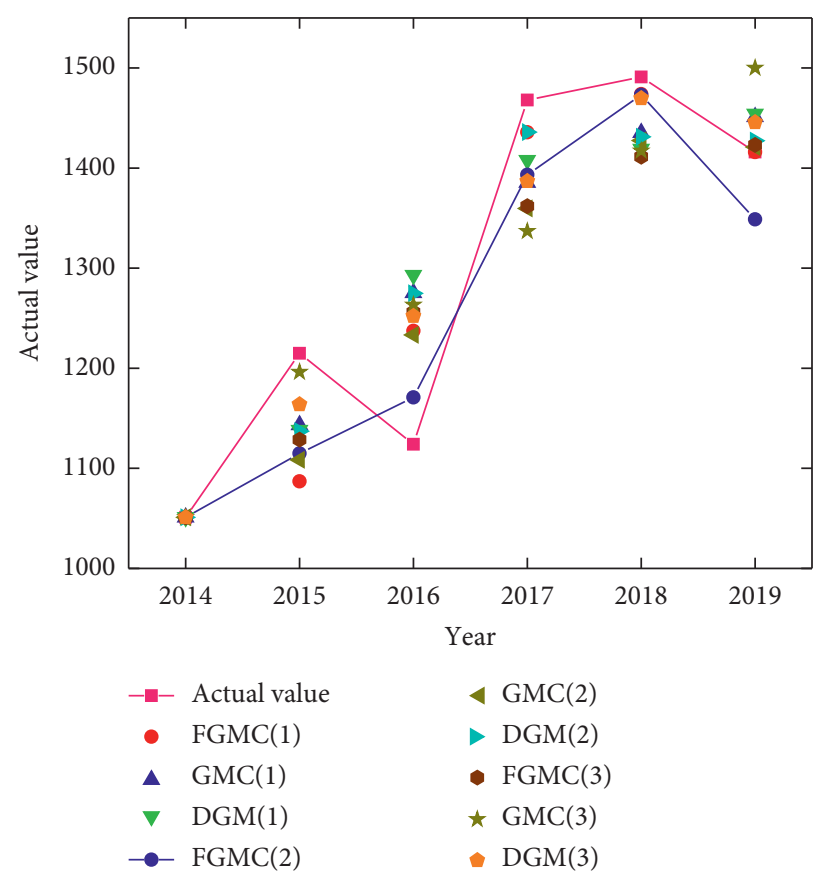

FIGURE 3: Prediction results of air pollution attention under the different industries influence.

solved. In fact, due to objective conditions (technological level), the utilization rate of resources in industrial production activities has been difficult to approach the "ideal state." Industry, especially heavy industry, is still the key source of air pollution in Handan area. Interestingly, even though the air reports that smog has improved, the public is still deeply skeptical. For the public, their focus is not on data, but on feelings. When the public smells the pungent smell in the air, they cannot see the road ahead because of the smog, and the official reports cannot give them satisfactory answers, which stimulates the public's awareness of selfinquiring information. The public will learn about air pollution information through various information channels, social software, search engines, and so on. Naturally, Baidu Index, as the largest search engine in China, can well reflect the public's attention to air pollution. The more serious the air pollution felt by the public, the more it can stimulate their search behavior and reflect the public's attention to air 
pollution. In short, the faster the industrial development, the higher the public's attention to air pollution, which is consistent with the coefficient $(2.173904>0)$ of influencing factors (industrial added value).

Compared with the past impact of the added value of the secondary industry on air pollution attention, it is more important to study the public attention caused by the future industrial development. Therefore, considering the different development conditions of the secondary industry, the development of the secondary industry is divided into five rates, and the results of different industrial development rates are taken as influencing factors to analyze the future air pollution attention. Table 4 shows the added value of the secondary industry from 2020 to 2024 under different growth rates.

The discrete form of the model is

$$
\begin{aligned}
\hat{x}_{1}^{(0.00523)}(t)= & x_{1}^{(0)}(1) e^{-0.902474(t-1)} \\
& +\sum_{\tau=2}^{t}\left\{e^{-0.902474(t-\tau+0.5)} \frac{f(\tau)+f(\tau-1)}{2}\right\} .
\end{aligned}
$$

where

$$
f(t)=2.173904 x_{2}^{(0)}(t)-2227.69 .
$$

Then, the corresponding air pollution attention can be obtained and is given in Table 5.

As shown in Table 5, the air quality attention of Handan from 2020 to 2024 shows different trends under five different industrial growth rates. It can be seen more intuitively from Figure 4 that the industrial growth rate increases and the attention of air pollution increases. Industrial growth rate declines. The attention to air quality will decline. Moreover, when the added value becomes larger or smaller, the attention of air pollution increases or decreases faster, so the added value of the secondary industry in Handan has a significant impact on the attention of air pollution.

\subsection{Relationship between the Secondary Industry Added Value} and Air Pollution Attention in Xingtai. Xingtai, north city of Handan, is the eastern transport corridor for Shanxi coal, and many national and provincial trunk roads pass through the city. So there are many heavy transport vehicles in transit and heavy pollution, which aggravates the regional air pollution. At the same time, there are more than 130 large coal-fired enterprises within a radius of 25 kilometers around Xingtai, with an annual coal consumption of more than 18 million tons. In addition, Xingtai is located in the groove zone in front of Taihang Mountain, with low terrain and low wind speed, which is easy to form an inversion layer, which is not conducive to the diffusion of pollutants. Because there are pollution sources all around Xingtai, no matter what season or wind direction, pollutants will float to the urban area, which will bring great threat to the physical and mental health of Xingtai people. Therefore, it is necessary to study the influence of the secondary industry development on air pollution attention.
Table 6 shows the added value of the primary, secondary, and tertiary industries in Xingtai from 2014 to 2019, the proportion of the total output value, and the attention to air pollution. It can be seen from Table 6 that the secondary industry is the key development industry in Xingtai and has been the focus of its industrial development for many years. However, the proportion has declined in recent years (from 0.5 to 0.39 ), which indicates to a certain extent that the local government has consciously reduced the proportion of the secondary industry. Considering the sources of air pollution, we have reasons to believe that this practice is based on the idea of reducing air pollution. Even so, the secondary industry still occupies a large proportion and will remain a main source of air pollution in this region for a long time to come. Therefore, the added value of the secondary industry is used as the influencing factor, and $\operatorname{FGMC}(1,2)$ model is used to predict the degree of attention. The model is as follows:

$$
\begin{aligned}
& \frac{\mathrm{d} x_{1}^{(0.886744)}(t)}{\mathrm{d} t}+0.988171 x_{1}^{(0.886744)}(t) \\
& =1.250947 x_{2}^{(0.886744)}(t)+550.9289,
\end{aligned}
$$

Xingtai is adjacent to Handan, and its air pollution and public feelings are similar. Therefore, the added value of the secondary industry affects the public's attention to air pollution in the same way, which is consistent with the driving coefficient of the secondary industry in the model $(2.802978>0)$. This indicates that the model has practical significance. At the same time, the fitting value of attention under the influence of the secondary industry can be obtained. The results are shown in Table 7.

It can be known from Table 7 that the fitting accuracy of FGMC $^{0.886744}(1,2)$ model reaches $6.94 \%$. This indicates that the accuracy of this model is very good, and it can be used to predict the public's attention to air pollution in Xingtai. Similarly, the secondary industry added value at different development rates is taken as the influencing factor to predict the public air pollution attention in the future. The added value of the secondary industry with different development rates is shown in Table 8 .

The discrete form of the model is

$$
\begin{aligned}
\widehat{x}_{1}^{(0.886744)}(t)= & x_{1}^{(0)}(1) e^{-0.988171(t-1)} \\
& +\sum_{\tau=2}^{t}\left\{e^{-0.988171(t-\tau+0.5)} \frac{f(\tau)+f(\tau-1)}{2}\right\} .
\end{aligned}
$$

where

$$
f(t)=1.250947 x_{2}^{(0)}(t)+550.9289 .
$$

By substituting different secondary industry added value in Table 8 into the model eq. (15), the corresponding air pollution attention from 2020 to 2024 can be obtained. The results are shown in Table 9.

As shown in Table 9, the air quality attention of Xingtai from 2020 to 2024 shows different trends under different 
TABLE 4: The air pollution attention at different growth rates of secondary industry in Handan.

\begin{tabular}{|c|c|c|c|c|c|}
\hline \multirow{2}{*}{ Year } & \multicolumn{5}{|c|}{ Industrial growth rate } \\
\hline & $-10 \%$ & $-5 \%$ & $5 \%$ & $10 \%$ & $20 \%$ \\
\hline 2020 & 1399.1 & 1476.9 & 1632.3 & 1710.1 & 1865.5 \\
\hline 2021 & 1259.2 & 1403.0 & 1713.9 & 1881.1 & 2238.6 \\
\hline 2022 & 1133.3 & 1332.9 & 1799.6 & 2069.2 & 2686.3 \\
\hline 2023 & 1020.0 & 1266.2 & 1889.6 & 2276.1 & 3223.6 \\
\hline 2024 & 918.0 & 1202.9 & 1984.1 & 2503.7 & 3868.3 \\
\hline
\end{tabular}

TABLE 5: Air pollution attention under the influence of the secondary industry in Handan.

\begin{tabular}{|c|c|c|c|c|c|}
\hline \multirow{2}{*}{ Year } & \multicolumn{5}{|c|}{ Industry growth rate } \\
\hline & $-10 \%$ & $-5 \%$ & $5 \%$ & $10 \%$ & $20 \%$ \\
\hline 2020 & 1189.8 & 1243.6 & 1351.3 & 1405.1 & 1512.7 \\
\hline 2021 & 922.1 & 1097.3 & 1463.8 & 1655.1 & 2053.9 \\
\hline 2022 & 630.6 & 939.3 & 1626.3 & 2006.1 & 2842.6 \\
\hline 2023 & 347.7 & 781.5 & 1814.7 & 2422.8 & 3845.2 \\
\hline 2024 & 84.7 & 628.3 & 2019.6 & 2893.5 & 5070.8 \\
\hline
\end{tabular}

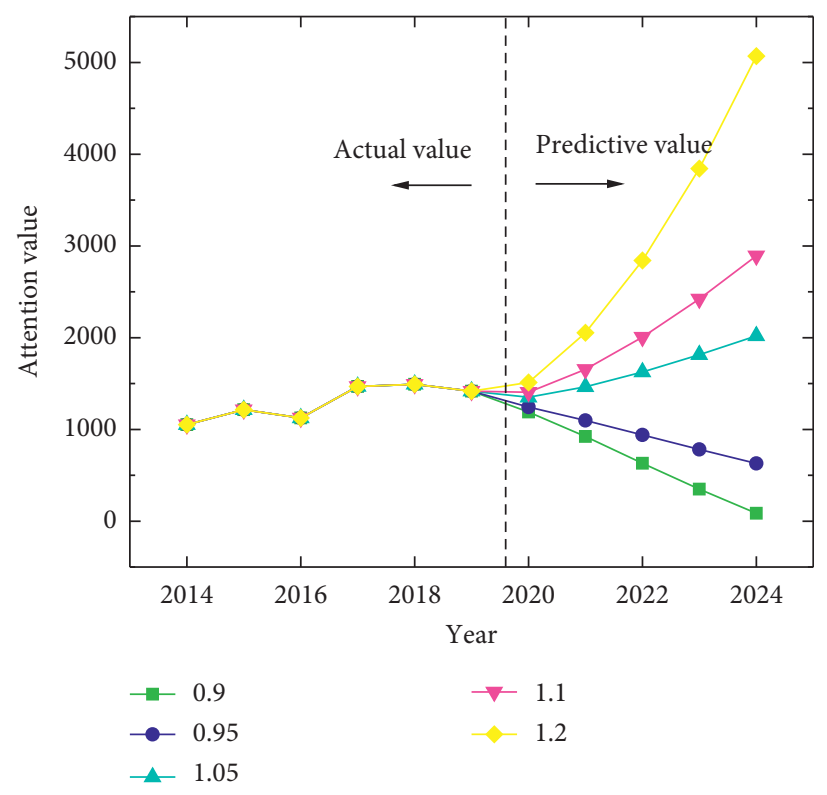

FIgURE 4: The development trend of air pollution attention in Handan at different industrial growth rates.

industrial growth rates. It can be seen more intuitively from Figure 5 that the industrial growth rate increases and the attention of air pollution increases. Industrial growth rate declines. The attention to air quality will decline. Moreover, when the added value becomes larger or smaller, the attention of air pollution increases or decreases faster, so the added value of the secondary industry in Xingtai has a significant impact on the attention of air pollution.

4.3. Relationship between the Secondary Industry Added Value and Air Pollution Attention in Shijiazhuang. Shijiazhuang is located on the east side of Taihang Mountain, with flat terrain, low altitude, typical warm temperate continental monsoon climate, prevailing northwest wind in winter, blocked and shielded by Taihang Mountains, and located in the "shadow zone" downwind direction. The weather conditions are static and stable, with little wind and easy accumulation of air. In addition, due to the effect of burning wind, the atmosphere is prone to inversion, stratification is relatively stable, and air is not easy to diffuse. Once pollutants are formed, they can only aggravate the pollution degree in this area, which makes the air quality worrying all year round. In terms of energy consumption, coal is mainly used, especially for heating and industrial power in winter. The consumption of coal exceeds the total annual consumption in Beijing, which is undoubtedly worse for Shijiazhuang with low terrain. Moreover, in recent years, 
TABLE 6: Attention to air pollution and the added value, the proportion of primary, secondary, and tertiary industry in Xingtai.

\begin{tabular}{lcccccr}
\hline \multirow{2}{*}{ Year } & \multirow{2}{*}{ Attention } & \multicolumn{3}{c}{ Industry added value (billion yuan) } \\
& \multicolumn{2}{c}{ Primary } & \multicolumn{2}{c}{ Secondary } & Tertiary \\
\hline 2014 & 831 & 273.4 & 0.16 & 836.5 & 0.50 & 558.2 \\
2015 & 965 & 275.6 & 0.16 & 793.6 & 0.45 & 695.5 \\
2016 & 902 & 269.7 & 0.14 & 904.9 & 0.46 & 780.2 \\
2017 & 1248 & 273.2 & 0.12 & 1070.1 & 0.48 & 0.33 \\
2018 & 1290 & 265.4 & 0.12 & 876.8 & 0.41 & 0.40 \\
2019 & 1097 & 283.5 & 0.13 & 833.1 & 0.39 & 1008.6 \\
\hline
\end{tabular}

TABLE 7: Fitting results of air pollution attention under the influence of secondary industry in Xingtai.

\begin{tabular}{lcc}
\hline Year & Actual value & FGMC $^{0.886744}(1,2)$ \\
\hline 2014 & 831 & 831.0 \\
2015 & 965 & 813.7 \\
2016 & 902 & 963.5 \\
2017 & 1248 & 1124.0 \\
2018 & 1290 & 1171.3 \\
2019 & 1097 & 1097.0 \\
MAPE & & $6.94 \%$ \\
\hline
\end{tabular}

TABLE 8: Secondary industry added value in Xingtai.

\begin{tabular}{lccccc}
\hline Year & & \multicolumn{3}{c}{ Growth rates } & \\
& $-10 \%$ & $-5 \%$ & $5 \%$ & $10 \%$ & 916.4 \\
2020 & 749.8 & 791.4 & 874.7 & 1008.0 & 999.7 \\
2021 & 674.8 & 751.8 & 918.5 & 1108.8 & 1199.6 \\
2022 & 607.3 & 714.3 & 964.4 & 1219.7 & 1439.5 \\
2023 & 546.6 & 678.5 & 1012.6 & 1341.7 \\
2024 & 491.9 & 644.6 & 1063.2 & 2072.9 \\
\hline
\end{tabular}

TABle 9: Attention of air pollution under the influence of the secondary industry in Xingtai.

\begin{tabular}{|c|c|c|c|c|c|}
\hline \multirow{2}{*}{ Year } & \multicolumn{5}{|c|}{ Growth rates } \\
\hline & $-10 \%$ & $-5 \%$ & $5 \%$ & $10 \%$ & $20 \%$ \\
\hline 2020 & 1019.8 & 1035.7 & 1067.5 & 1083.4 & 1115.2 \\
\hline 2021 & 929.8 & 981.1 & 1088.3 & 1144.3 & 1261.0 \\
\hline 2022 & 841.3 & 930.6 & 1129.6 & 1239.7 & 1482.5 \\
\hline 2023 & 758.9 & 883.3 & 1180.3 & 1355.5 & 1765.8 \\
\hline 2024 & 683.8 & 838.7 & 1236.5 & 1487.0 & 2112.6 \\
\hline
\end{tabular}

influenced by the integration of Beijing, Tianjin, and Hebei, the population of Shijiazhuang has surged, and the urban population has exceeded 5 million. Heating in nearby rural areas in winter is still dominated by coal burning, which produces a large number of pollutants such as dust, sulfides, and carbon compounds, resulting in continuous smog in urban areas in winter. Therefore, it is urgent to study the influence of the development of the secondary industry on air pollution in Shijiazhuang.

Table 10 shows the added value of the primary, secondary, and tertiary industry in Shijiazhuang from 2014 to 2019, the proportion of the total output value, and the attention to air pollution. It can be seen from the table that the secondary industry in Shijiazhuang accounts for a large proportion of its economic development. Interestingly, from 2014 to 2019, the added value of the secondary industry in Shijiazhuang has been declining, and the decline rate is very large (one third), accompanied by the continuous rise of the tertiary industry, which shows that Shijiazhuang has been reducing the proportion of the secondary industry in a planned way, which is helpful to reduce air pollution. However, air control is a long-term process, and $32 \%$ of industrial added value has also put great pressure on air control. Therefore, it is still necessary to understand the public's attention to air pollution in order to improve air quality and public health. Therefore, the FGMC $(1, N)$ model is used to predict the public's attention to air pollution with the added value of 


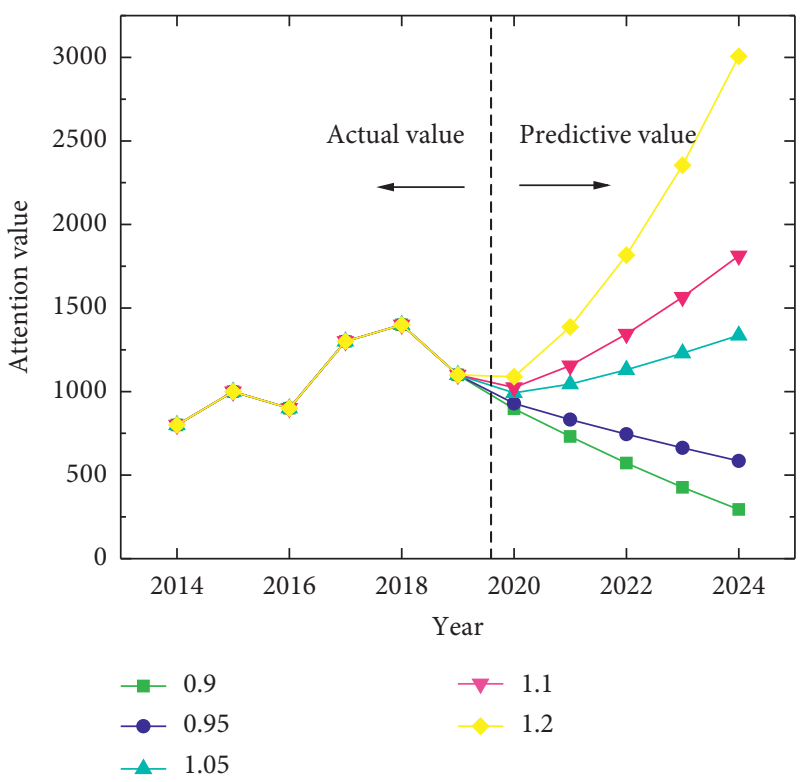

Figure 5: Attention to air pollution under the influence of secondary industry in Xingtai.

TABLE 10: Attention to air pollution and added value, proportion of primary, secondary, and tertiary industry in Shijiazhuang.

\begin{tabular}{lcccccr}
\hline \multirow{2}{*}{ Year } & Attention & \multicolumn{3}{c}{ Industry added value (billion yuan) } \\
& & \multicolumn{2}{c}{ Primary } & & Secondary & Tertiary \\
\hline 2014 & 2278 & 488.3 & 0.10 & 2439.3 & 0.48 & 2172.6 \\
2015 & 2161 & 494.4 & 0.09 & 2452.9 & 0.45 & 2493.3 \\
2016 & 2128 & 480.9 & 0.08 & 2638 & 0.45 & 2738.9 \\
2017 & 2418 & 480.5 & 0.07 & 2913.9 & 0.45 & 3066.4 \\
2018 & 2286 & 420.5 & 0.07 & 2285.5 & 0.38 & 0.47 \\
2019 & 2168 & 449.5 & 0.08 & 1831.7 & 0.32 & 3376.7 \\
\hline
\end{tabular}

Shijiazhuang's secondary industry as the influencing factor. Based on the data in Table 10, the following prediction model can be established:

$$
\begin{aligned}
& \frac{\mathrm{d} x_{1}^{(0.050481)}(t)}{\mathrm{d} t}+0.442577 x_{1}^{(0.050481)}(t) \\
& =0.502094 x_{2}^{0}(t)-245.163 .
\end{aligned}
$$

Based on the above discussion, we can know that the greater the added value of the secondary industry, the higher the public's attention to air pollution. This is consistent with the driving coefficient of the secondary industry in the model $(0.502094>0)$. Then, substituting the added value of Shijiazhuang's secondary industry from 2014 to 2019 into eq. (17), the fitting result of air pollution attention from 2014 to 2019 can be obtained, as shown in Table 11.

It can be known from Table 11 that the fitting accuracy of $\operatorname{FGMC}^{(0.050481)}(1,2)$ model reaches $1.77 \%(<10 \%)$, indicating that the accuracy of this model is very good, and it can be used to predict the public's attention to air pollution in Shijiazhuang. Similarly, the added value of five different development rates of the secondary industry is taken as the influencing factor to predict the public air pollution attention in the future. The added value of the secondary industry with different development rates is shown in Table 12.

The discrete form of the model is

$$
\begin{aligned}
\hat{x}_{1}^{(0.050481)}(t)= & x_{1}^{(0)}(1) e^{-0.442577(t-1)} \\
& +\sum_{\tau=2}^{t}\left\{e^{-0.442577(t-\tau+0.5)} \frac{f(\tau)+f(\tau-1)}{2}\right\},
\end{aligned}
$$

where

$$
f(t)=0.502094 x_{2}^{(0)}(t)-245.163 .
$$

By substituting different added values of the secondary industry from 2020 to 2024 in Table 12 into the model eq. (18), the corresponding air pollution attention of Shijiazhuang from 2020 to 2024 can be obtained. The results are shown in Table 13.

As shown in Table 13, the air quality attention of Shijiazhuang from 2020 to 2024 shows different trends under five different industrial growth rates. It can be seen more intuitively from Figure 6 that the industrial added rate increases and the attention of air pollution increases. Industrial added rate declines, and attention to air quality declines. 
TABLE 11: Fitting results of air pollution attention under the influence of secondary industry in Shijiazhuang.

\begin{tabular}{lcc}
\hline Year & Actual value & FGMC $^{(0.050481)}(1,2)$ \\
\hline 2014 & 2278 & 2278 \\
2015 & 2161 & 2161 \\
2016 & 2128 & 2183 \\
2017 & 2418 & 2310 \\
2018 & 2286 & 2331 \\
2019 & 2168 & 2133 \\
MAPE & & $1.77 \%$ \\
\hline
\end{tabular}

TABLE 12: The secondary industry added value in Shijiazhuang.

\begin{tabular}{|c|c|c|c|c|c|}
\hline \multirow{2}{*}{ Year } & \multicolumn{5}{|c|}{ Growth rate } \\
\hline & $-10 \%$ & $-5 \%$ & $5 \%$ & $10 \%$ & $20 \%$ \\
\hline 2020 & 1648.5 & 1740.1 & 1923.3 & 2014.9 & 2198.0 \\
\hline 2021 & 1483.7 & 1653.1 & 2019.4 & 2216.4 & 2637.6 \\
\hline 2022 & 1335.3 & 1570.5 & 2120.4 & 2438.0 & 3165.2 \\
\hline 2023 & 1201.8 & 1491.9 & 2226.4 & 2681.8 & 3798.2 \\
\hline 2024 & 1081.6 & 1417.3 & 2337.8 & 2950.0 & 4557.9 \\
\hline
\end{tabular}

TABLE 13: Attention to air pollution under the influence of secondary industry in Shijiazhuang.

\begin{tabular}{|c|c|c|c|c|c|}
\hline \multirow{2}{*}{ Year } & \multicolumn{5}{|c|}{ Different growth rates } \\
\hline & $-10 \%$ & $-5 \%$ & $5 \%$ & $10 \%$ & $20 \%$ \\
\hline 2020 & 1882.3 & 1900.6 & 1937.5 & 1955.9 & 1992.8 \\
\hline 2021 & 1655.0 & 1719.0 & 1853.2 & 1923.1 & 2068.5 \\
\hline 2022 & 1448.7 & 1570.9 & 1841.5 & 1989.9 & 2314.5 \\
\hline 2023 & 1261.9 & 1445.6 & 1877.9 & 2128.8 & 2708.1 \\
\hline 2024 & 1092.8 & 1336.2 & 1946.9 & 2322.8 & 3243.0 \\
\hline
\end{tabular}

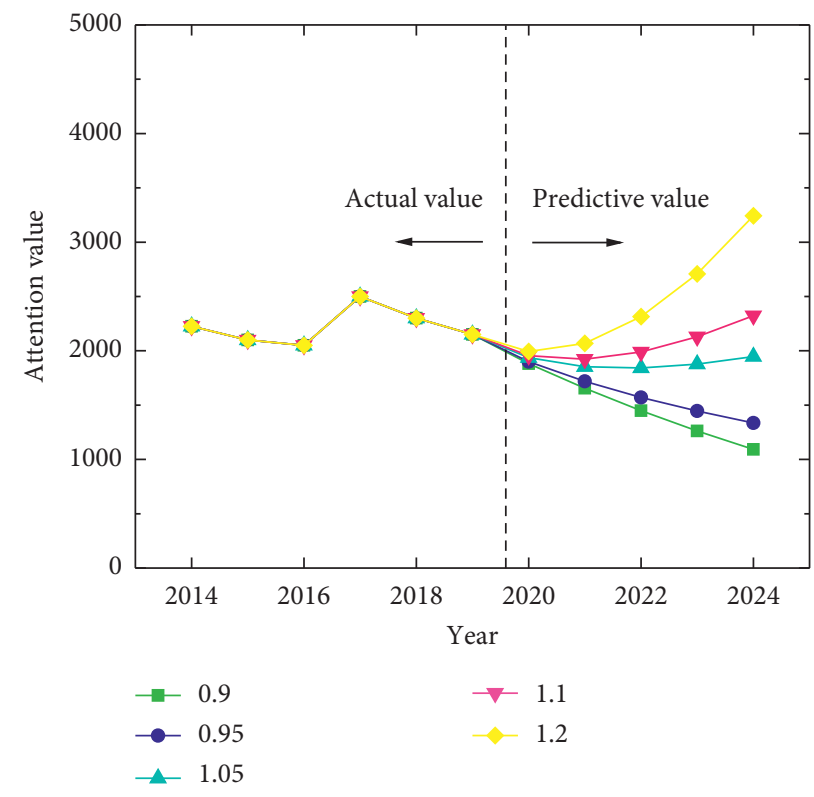

FIGURE 6: Attention to air pollution under the influence of secondary industry with different development rates in Shijiazhuang. 
TABLE 14: Industrial proportion and driving factor of model in Handan, Xingtai, and Shijiazhuang.

\begin{tabular}{lccr}
\hline $\begin{array}{l}\text { Driving factor } \\
\text { Year }\end{array}$ & $\begin{array}{c}\text { Handan } \\
2.17\end{array}$ & $\begin{array}{c}\text { Xingtai } \\
1.25\end{array}$ & $\begin{array}{c}\text { Shijiazhuang } \\
0.50\end{array}$ \\
\hline 2014 & & Proportion of industrial structure (Primary:Secondary:Tertiary) & $0.10: 0.48: 0.43$ \\
2015 & $0.13: 0.50: 0.37$ & $0.16: 0.50: 0.33$ & $0.09: 0.45: 0.46$ \\
2016 & $0.13: 0.48: 0.39$ & $0.16: 0.45: 0.39$ & $0.08: 0.45: 0.47$ \\
2017 & $0.13: 0.47: 0.40$ & $0.12: 0.46: 0.40$ & $0.07: 0.45: 0.47$ \\
2018 & $0.11: 0.49: 0.40$ & $0.12: 0.41: 0.47$ & $0.07: 0.38: 0.56$ \\
2019 & $0.09: 0.45: 0.46$ & $0.13: 0.39: 0.47$ & $0.08: 0.32: 0.61$ \\
\hline
\end{tabular}
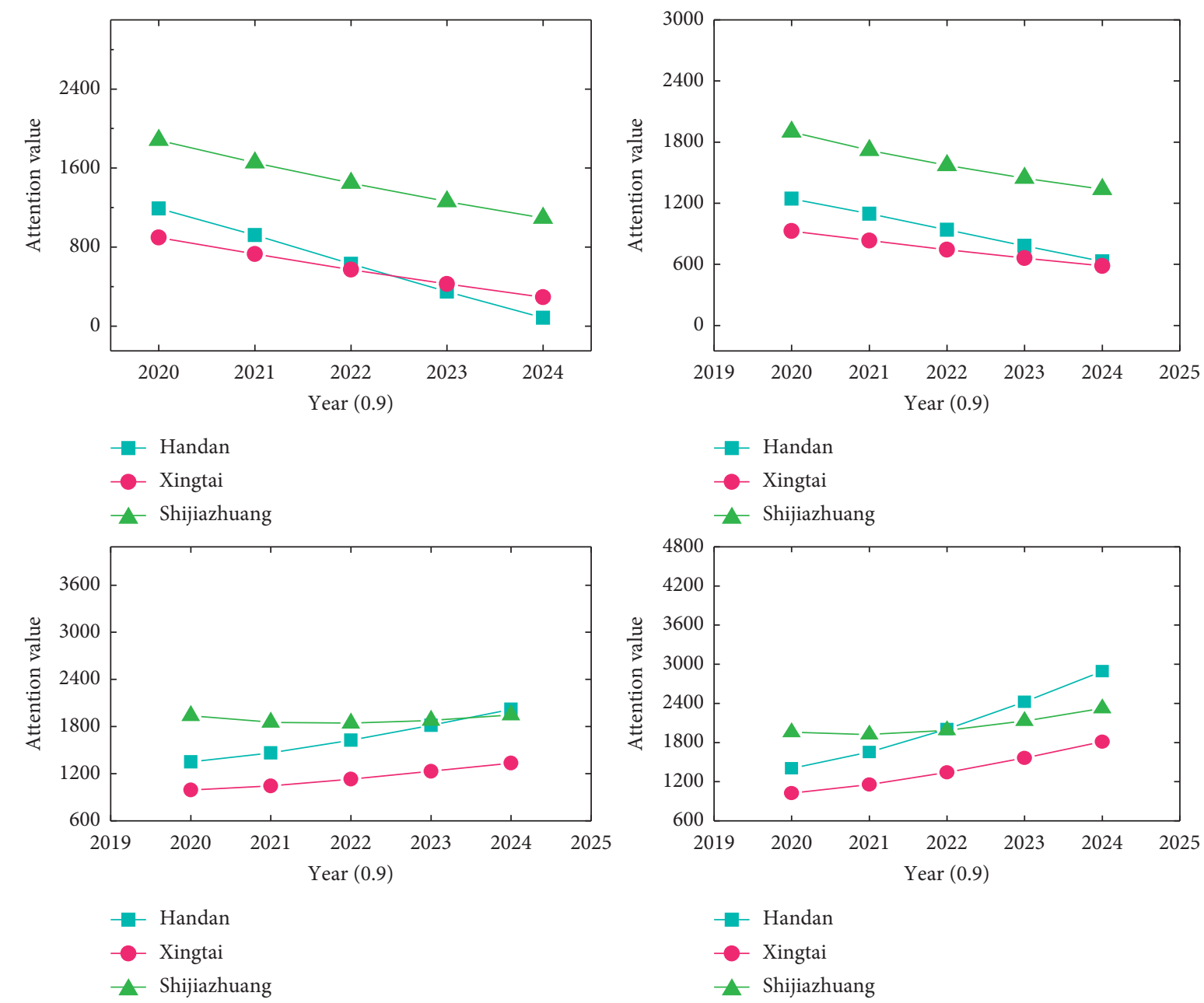

Xingtai

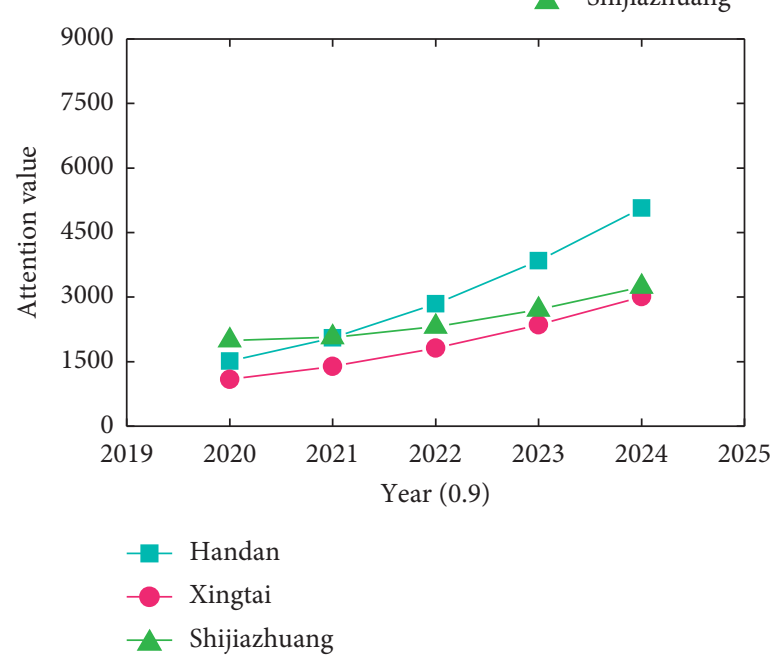

Figure 7: Public attention to air pollution under the influence of secondary industry with different growth rates. 
Moreover, when the added value becomes larger or smaller, the attention of air pollution increases or decreases faster, so the added value of the secondary industry in Shijiazhuang has a significant impact on the attention of air pollution.

4.4. Comparative Analysis. With the coordinated development of Beijing-Tianjin-Hebei, energy consumption is inevitable. However, in order to protect the environment around the capital, many highly polluting energy enterprises were forced to migrate. Handan, Xingtai, and Shijiazhuang are located in the southernmost part of Hebei Province, which naturally become the gathering places of highly polluting enterprises. For many years, the pollutants produced by industrial development have caused serious damage to the air quality in Handan, Xingtai, and Shijiazhuang, and the air pollution problem has been plaguing the local people. Therefore, taking the added value of the secondary industry as the influencing factor, the prediction models of air pollution attention in three cities were constructed, respectively. From the results of the model, the development of the secondary industry in three cities has a great impact on the public's attention to air pollution.

According to the driving coefficient of the model listed in Table 14, the driving coefficient of Handan is the largest (2.17), which indicates that the industrial added value of the secondary industry in Handan has the greatest influence on the attention of air pollution. Judging from the proportion of industrial development, the added value of Handan's secondary industry accounts for a large proportion, accounting for almost half of the total industrial added value. Geographically, Handan is located in the southernmost part of Hebei Province, with the largest number of enterprises migrating and relatively weak pollution prevention and control. Xingtai's driving coefficient (1.25) is slightly lower than Handan's. From the industrial distribution ratio, Xingtai's secondary industry also accounts for a larger proportion, slightly lower than Handan's, which is very easy to attract public attention, thus increasing public attention. Geographically, Xingtai is located between Handan and Shijiazhuang, and the pollutants in both cities are likely to spread, which undoubtedly increases the public's attention about air pollution in Xingtai. Shijiazhuang has the lowest driving coefficient (0.50), which indicates that the added value of Shijiazhuang's secondary industry has the lightest influence on air pollution attention. From the perspective of industrial development ratio, the added value of Shijiazhuang's secondary industry is less than one-third of the total added value, and from 2014 to 2019, the added value of Shijiazhuang's secondary industry showed a declining trend, which also weakened the public's attention about air pollution based on the development of the secondary industry to a certain extent. Geographically, Shijiazhuang is closest to the Beijing-Tianjin-Hebei region, and Shijiazhuang is also the capital of Hebei Province. It has a strong air control and high public satisfaction, which is one of the reasons for the low public attention to air pollution.

In order to study the public's attention to air pollution in the future, the added values of the secondary industry in three cities were assumed respectively, and the changes of public attention to air pollution in different growth situations of the secondary industry were predicted by FGMC(1, 2) model. It can be seen from Figure 7 that when the added value of the secondary industry develops at a speed of $90 \%$, the public's attention to air pollution in the three cities will be significantly reduced, especially for Handan, which has the most significant impact. On the contrary, if the added value of the secondary industry in the three cities continues to accelerate at a rate of $120 \%$, the public's attention to air pollution will increase significantly in 2024, especially in Handan City, which will increase to 3.58 times that in 2019, which is an amazing number. This may mean serious air pollution and psychological problems such as depression, fear, fear, anxiety, and irritability.

\section{Conclusion and Implication}

Air pollution is already the most serious environmental problem, especially in the Beijing-Tianjin-Hebei region of China. Handan, Xingtai, and Shijiazhuang, located in the southernmost part of Hebei Province, are the areas with the most serious air pollution in the Beijing-Tianjin-Hebei region. Due to the rapid development of the secondary industry, air pollution in the three cities is very serious, which causes great harm to the public's physical and mental health. Research shows that the higher the public's attention to air pollution, the more serious the air pollution, and the more likely it is for the public to have psychological problems. Therefore, in order to better understand air pollution and public mental health, we use the added value of the secondary industry as the influencing factor and use FGMC(1, 2) model to predict the public's attention to air pollution. The research shows the following:

(1) Compared with $\operatorname{GMC}(1,2)$ and $\operatorname{DGM}(1,2)$ models, FGMC $(1,2)$ model is more suitable for public attention to air pollution.

(2) The air pollution problems in Handan, Xingtai, and Shijiazhuang are mainly caused by industrial production. Therefore, compared with the primary industry and the tertiary industry, it is more effective to use the added value of the secondary industry as an influencing factor to study the public's attention to air pollution.

(3) The forecast results from 2020 to 2024 show that the faster the growth of the secondary industry, the higher the public's attention to air pollution. And this phenomenon is more obvious in cities with higher industrialization.

Therefore, combined with the public's attention to air pollution, the following suggestions are put forward for the air pollution problems in Handan, Xingtai, and Shijiazhuang:

(1) Adjust the industrial structure. Industrial production produces a large number of pollutants, so it is necessary to shift the focus of economic development to the tertiary industry, so as to reduce air pollution 
from the source of pollution. In fact, from the industrial development of Shijiazhuang from 2014 to 2019 , we can find that the city is already doing such work and has achieved certain results.

(2) Build an air quality information exchange platform. To a great extent, the public's attention to air pollution is not conducive to air control but rather increases troubles. Therefore, it is necessary to strengthen the exchange of information related to air quality, so as to reduce public panic and public attention to air pollution. This will not only help improve the public's understanding of air pollution, but also encourage the public to cooperate with environmental protection departments to carry out air treatment and, at the same time, effectively avoid the public's psychological problems such as anxiety, fear, and depression.

However, this paper still has some limitations. Firstly, although Baidu Index is based on big data statistics, it cannot cover all the people. Secondly, the air pollution attention based on Baidu index lacks a more rigorous definition.

In a word, based on Baidu index data and industrial development, the research on public air pollution attention is effective, and some suggestions on air control in Handan, Xingtai, and Shijiazhuang in the future were given. Future research can also be carried out in other cities and regions, and only some changes are needed. First of all, the influencing factors should be selected according to the local geographical location, industrial development, and development planning. Secondly, for the definition of attention, Baidu keyword types should be further perfected, and exponential weighting treatment can be carried out for different factors such as age, occupation, and knowledge level.

\section{Data Availability}

The data used to support the findings of this study are available from the corresponding author upon request.

\section{Conflicts of Interest}

The authors declare that they have no conflicts of interest.

\section{Acknowledgments}

This study was supported by the National Natural Science Foundation of China (71871084) and the Excellent Young Scientist Foundation of Hebei Education Department (SLRC2019001).

\section{References}

[1] A. A. Almetwally, M. Bin-Jumah, and A. A. Allam, "Ambient air pollution and its influence on human health and welfare: an overview," Environmental Science and Pollution Research, vol. 27, no. 20, pp. 24815-24830, 2020.

[2] O. K. Kurt, J. Zhang, and K. E. Pinkerton, "Pulmonary health effects of air pollution," Current Opinion in Pulmonary Medicine, vol. 22, no. 2, pp. 138-143, 2016.
[3] H. Gu, W. Yan, E. Elahi, and Y. Cao, "Air pollution risks human mental health: an implication of two-stages least squares estimation of interaction effects," Environmental Science and Pollution Research, vol. 27, no. 2, pp. 2036-2043, 2020.

[4] X. Luo, H. Bing, Z. Luo, Y. Wang, and L. Jin, "Impacts of atmospheric particulate matter pollution on environmental biogeochemistry of trace metals in soil-plant system: a review," Environmental Pollution, vol. 255, Article ID 113138, 2019.

[5] J. Lou, Y. Wu, P. Liu, S. H. Kota, and L. Huang, "Health effects of climate change through temperature and air pollution," Current Pollution Reports, vol. 5, no. 3, pp. 144-158, 2019.

[6] D. Gautam and N. B. Bolia, "Air pollution: impact and interventions," Air Quality, Atmosphere \& Health, vol. 13, no. 2, pp. 209-223, 2020.

[7] Y.-C. Lin, S.-C. Hsu, C. C.-K. Chou et al., "Wintertime haze deterioration in Beijing by industrial pollution deduced from trace metal fingerprints and enhanced health risk by heavy metals," Environmental Pollution, vol. 208, pp. 284-293, 2016.

[8] T. Wang, L. Xue, P. Brimblecombe, Y. F. Lam, L. Li, and L. Zhang, "Ozone pollution in China: a review of concentrations, meteorological influences, chemical precursors, and effects," Science of the Total Environment, vol. 575, pp. 1582-1596, 2017.

[9] X. Cao, Y. Jie, N. Wang, and Z. L. Wang, "Triboelectric nanogenerators driven self-powered electrochemical processes for energy and environmental science," Advanced Energy Materials, vol. 6, no. 23, Article ID 1600665, 2016.

[10] M. U. Farooq, U. Shahzad, S. Sarwar, and L. ZaiJun, "The impact of carbon emission and forest activities on health outcomes: empirical evidence from China," Environmental Science and Pollution Research, vol. 26, no. 13, pp. 1289412906, 2019.

[11] H. Ma and G. He, "How does environmental concern influence public acceptability of congestion charging? evidence from Beijing," Ecosystem Health and Sustainability, vol. 6, no. 1, Article ID 1722033, 2020.

[12] Y. Song, A. Zhou, and M. Zhang, "Exploring the effect of subjective air pollution on happiness in China," Environmental Science and Pollution Research, vol. 27, no. 36, pp. 43299-43311, 2020.

[13] C. M. Wang and Y. E. Chun-Ming, "Attention degree of haze based on information diffusion theory," Logistics Engineering \& Management, vol. 38, no. 6, pp. 187-190, 2016.

[14] H. Zhang, L. Weng, D. Yang, and Y. Dai, "Application of spatial autocorrelation analysis to citizen's attention of fog and haze based on Baidu index," Journal of Subtropical Resources \& Environment, vol. 24, no. 3, pp. 61-68, 2017.

[15] G. K. Gao and D. L. Li, "Study on the influencing factors of regional difference on haze attention," Science Technology \& Industry, vol. 17, no. 12, pp. 46-50, 2017.

[16] B. Fu, K. Kurisu, K. Hanaki, and Y. Che, "Influential factors of public intention to improve the air quality in China," Journal of Cleaner Production, vol. 209, pp. 595-607, 2019.

[17] S. Sun, L. Li, Z. Wu, A. Gautam, J. Li, and W. Zhao, "Variation of industrial air pollution emissions based on VIIRS thermal anomaly data," Atmospheric Research, vol. 244, Article ID 105021, 2020.

[18] Y. Chen and J. Wang, "Ecological security early-warning in central Yunnan province, China, based on the gray model," Ecological Indicators, vol. 111, Article ID 106000, 2020.

[19] S. Li, B. Zeng, X. Ma, and D. Zhang, "A novel grey model with a three-parameter background value and its application in 
forecasting average annual water consumption per capita in urban areas along the Yangtze River basin," Journal of Grey System, vol. 32, no. 1, pp. 118-132, 2020.

[20] B. Zeng, M. Zhou, X. Liu, and Z. Zhang, "Application of a new grey prediction model and grey average weakening buffer operator to forecast China's shale gas output," Energy Reports, vol. 6, pp. 1608-1618, 2020.

[21] G. M. Duman, E. Kongar, and S. M. Gupta, "Estimation of electronic waste using optimized multivariate grey models," Waste Management, vol. 95, pp. 241-249, 2019.

[22] X. Ma, M. Xie, W. Wu, B. Zeng, Y. Wang, and X. Wu, "The novel fractional discrete multivariate grey system model and its applications," Applied Mathematical Modelling, vol. 70, pp. 402-424, 2019.

[23] L. Wu, X. Gao, Y. Xiao, Y. Yang, and X. Chen, "Using a novel multi-variable grey model to forecast the electricity consumption of Shandong province in China," Energy, vol. 157, pp. 327-335, 2018.

[24] S. Ding, "A novel discrete grey multivariable model and its application in forecasting the output value of China's hightech industries," Computers \& Industrial Engineering, vol. 127, pp. 749-760, 2019.

[25] Z.-X. Wang and Q. Li, "Modelling the nonlinear relationship between $\mathrm{CO}_{2}$ emissions and economic growth using a PSO algorithm-based grey verhulst model," Journal of Cleaner Production, vol. 207, pp. 214-224, 2019.

[26] L. Wu and Z. Xu, "Analyzing the air quality of Beijing, Tianjin, and Shijiazhuang using grey verhulst model," Air Quality, Atmosphere \& Health, vol. 12, no. 12, pp. 1419-1426, 2019.

[27] P.-p. Xiong, W.-j. Yan, G.-z. Wang, and L.-l. Pei, "Grey extended prediction model based on IRLS and its application on smog pollution," Applied Soft Computing, vol. 80, pp. 797809, 2019.

[28] Z. Xu, M. Dun, and L. Wu, "Prediction of air quality based on hybrid grey double exponential smoothing model," Complexity, vol. 2020, Article ID 9427102, 13 pages, 2020.

[29] L. Jiang, S. He, and H. Zhou, "Spatio-temporal characteristics and convergence trends of PM2.5 pollution: a case study of cities of air pollution transmission channel in Beijing-TianjinHebei region, China," Journal of Cleaner Production, vol. 256, Article ID 120631, 2020.

[30] H. Xu, Z. Xiao, K. Chen et al., "Spatial and temporal distribution, chemical characteristics, and sources of ambient particulate matter in the Beijing-Tianjin-Hebei region," Science of the Total Environment, vol. 658, pp. 280-293, 2019.

[31] B. Zhao, S. Wang, D. Ding et al., "Nonlinear relationships between air pollutant emissions and PM2.5-related health impacts in the Beijing-Tianjin-Hebei region," Science of the Total Environment, vol. 661, pp. 375-385, 2019.

[32] J. Wang, L. Zhang, X. Niu, and Z. Liu, "Effects of PM2.5 on health and economic loss: evidence from Beijing-TianjinHebei region of China," Journal of Cleaner Production, vol. 257, Article ID 120605, 2020.

[33] X. Chang, S. Wang, B. Zhao et al., "Contributions of inter-city and regional transport to PM2.5 concentrations in the Beijing-Tianjin-Hebei region and its implications on regional joint air pollution control," Science of the Total Environment, vol. 660, pp. 1191-1200, 2019.

[34] J. Gao, K. Wang, Y. Wang et al., "Temporal-spatial characteristics and source apportionment of PM2.5 as well as its associated chemical species in the Beijing-Tianjin-Hebei region of China," Environmental Pollution, vol. 233, pp. 714$724,2018$.
[35] J. Xing, F. Zhang, Y. Zhou et al., "Least-cost control strategy optimization for air quality attainment of Beijing-TianjinHebei region in China," Journal of Environmental Management, vol. 245, pp. 95-104, 2019.

[36] J. Li, L. Tang, and S. Wang, "Forecasting crude oil price with multilingual search engine data," Physica A-Statistical Mechanics and Its Applications, vol. 551, Article ID 124178, 2020.

[37] Y. Liu, G. Peng, L. Hu, J. Dong, and Q. Zhang, "Using Google trends and Baidu index to analyze the impacts of disaster events on company stock prices," Industrial Management \& Data Systems, vol. 120, no. 2, pp. 350-365, 2020.

[38] Z. H. Yang, J. G. Liu, C. R. Yu, and J. T. Han, "Quantifying the effect of investors' attention on stock market," Plos One, vol. 12, no. 5, Article ID e0176836, 2017.

[39] R. Zhao, X. Xiong, and D. Shen, "Investor attention and performance of IPO firms: evidence from online searches," Physica A: Statistical Mechanics and Its Applications, vol. 508, pp. 342-348, 2018.

[40] S. Zhong, Z. Yu, and W. Zhu, "Study of the effects of air pollutants on human health based on Baidu indices of disease symptoms and air quality monitoring data in Beijing, China," International Journal of Environmental Research and Public Health, vol. 16, no. 6, 1014 pages, 2019.

[41] B. Zeng, H. Duan, and Y. Zhou, "A new multivariable grey prediction model with structure compatibility," Applied Mathematical Modelling, vol. 75, pp. 385-397, 2019. 